\title{
Echocardiographic pattern of posterior mitral valve leaflet movement after mitral valve repair
}

\author{
R. D. THOMAS, D. A. S. MARY, AND M. I. IONESCU \\ From the Departments of Cardiology and Cardiothoracic Surgery, Leeds General Infirmary, and the \\ Department of Cardiovascular Studies, University of Leeds
}

SUMMARY The pattern of movement of the posterior leaflet at the time of opening of the stenosed mitral valve has been described as either anterior or posterior in direction.

In 32 patients who underwent mitral annuloplasty, the anatomical features of the mitral apparatus were correlated with the postoperative echocardiographic pattern of movement of the posterior leaflet. Anterior movement of the posterior leaflet was associated with extensive disease of this leaflet, and posterior movement with minimal disease. No relation was found between valve orifice or anterior leaflet mobility and the pattern of movement of the posterior leaflet.

One of the earliest applications of echocardiography was in the diagnosis of mitral valve disease (Edler and Gustafson, 1957). Among the diagnostic criteria now used, emphasis is placed on the pattern of movement of the posterior leaflet during mitral valve opening. When the posterior leaflet moves in an anterior direction, that is parallel to the anterior leaflet, this is considered to indicate mitral stenosis, in contrast to the normal mitral valve where the two leaflets move in opposite directions (Duchak et al., 1972; McLaurin et al., 1973; Cope et al., 1975). However, while anterior movement of the posterior leaflet is accepted as a reliable sign to rule out the presence of a normal mitral valve, posterior movement of this leaflet has been reported in patients with mitral stenosis (Levisman et al., 1975). This finding imposes limitations on the use of pattern analysis in the diagnosis of mitral stenosis.

The mechanism of this contrasting pattern of posterior leaflet movement is not known. Factors such as commissural adhesion, shortening of the chordae tendineae, or mobility of the posterior leaflet or the mitral ring have been implicated (Duchak et al., 1972; Levisman et al., 1975; Feigenbaum, 1976; Henry and Kastl, 1977). In the present report, the echocardiographic appearance of the posterior leaflet has been studied in patients after mitral annuloplasty. This surgical procedure allows direct assessment of the valve apparatus, and the operative findings help to explain the different patterns of movement.

Received for publication 29 June 1978

\section{Patients and methods}

Echocardiographic studies of both mitral valve leaflets were performed in 32 consecutive patients immediately after, and at varying intervals, for a period of up to 1 month, after mitral annuloplasty. The patients comprised 24 women and 8 men, with an age range from 19 to 66 years (mean 45 years).

The aetiology of mitral valve disease was rheumatic in 28 patients, congenital in 2, and degenerative in 2. Twelve of the 28 patients had pure or predominant mitral regurgitation and $16 \mathrm{had}$ mixed mitral valve disease. All the patients had open mitral annuloplasty (Wooler et al., 1962), the indications for which have been previously described (Mary et al., 1973). In addition to mitral annuloplasty, one patient required plication of the posterior leaflet and one closure of an atrial septal defect. Six other patients had tricuspid annuloplasty and 7 had aortic valve replacement.

At operation the condition of the posterior leaflet was classified into 2 categories. Firstly, minimal disease, in which the leaflet was either normal, minimally thickened, or only thickened at the commissures, and with retained pliability. Secondly, extensive disease, in which the leaflet was thickened and fibrosed with impaired pliability. After mitral annuloplasty a direct estimate of the anatomical dimensions of the mitral valve orifice was made and this was expressed in relation to body surface area as previously described (Mary et al., 1973).

Echocardiography was performed using a Smith- 
Kline Ekoline 20 ultrasonoscope and a $2 \cdot 25 \mathrm{MHz}$ transducer focused at $10 \mathrm{~cm}$, and recorded by Polaroid photography or with a Cambridge multichannel strip chart recorder. By angulating the transducer, $M$-mode sector scans were obtained at different sagittal planes through the mitral valve, from the base of the heart to the apex (Feigenbaum, 1972). At the level of the mitral valve, a transverse scan was performed to cover a wide area of the mitral leaflets. In all patients distinct echoes were obtained from the anterior

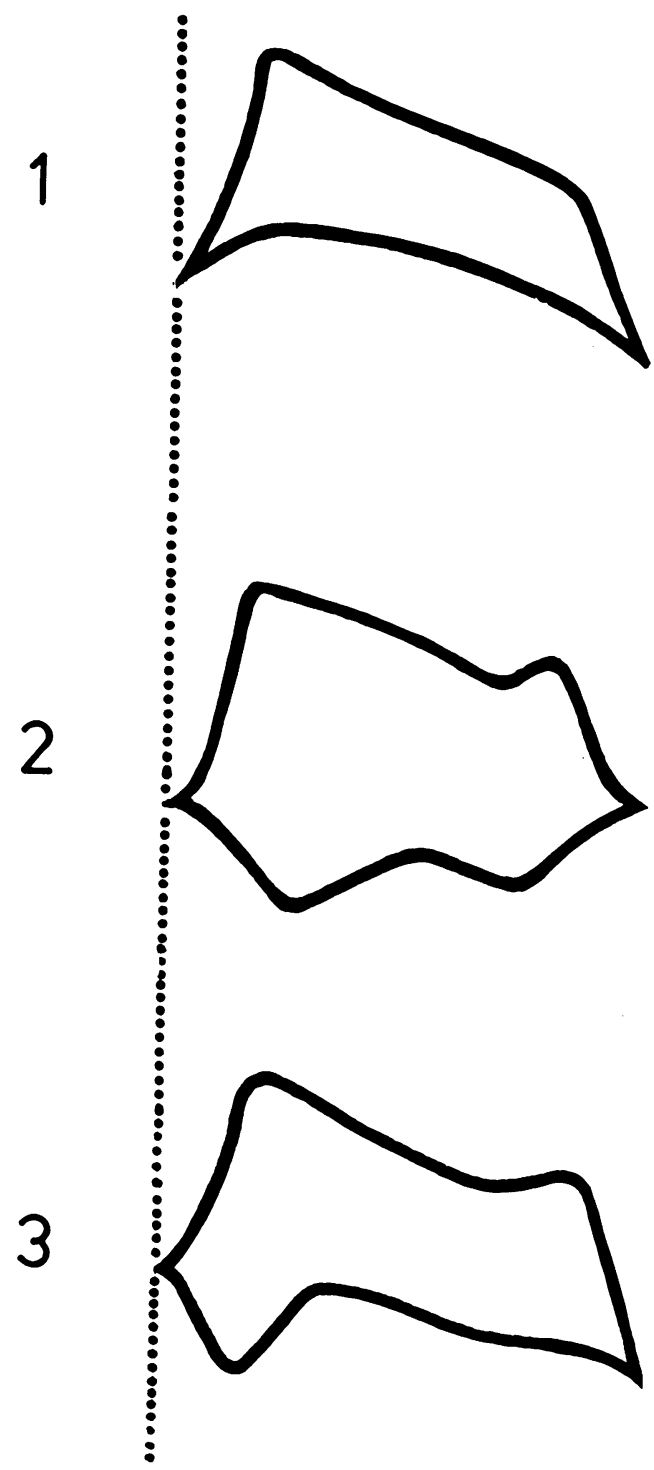

Fig. 1 Diagram of the 3 patterns of posterior leaflet movement after mitral annuloplasty and posterior leaflets and the latter was always separated from the mitral valve ring. The diastolic closure rate (EF slope-measured as the $\mathrm{EF}_{0}$ slope) and amplitude of excursion of the anterior leaflet (CE amplitude) were obtained from recordings where these values were greatest (Edler, 1967). An average of at least 4 cardiac cycles was used.

\section{Results}

In the 32 patients studied 3 patterns of movement of the posterior leaflet were observed (Fig. 1). These patterns were type 1 , in which the initial movement of the posterior leaflet, at the time of valve opening, was in the same direction as the anterior leaflet. In types 2 and 3, the initial movement of the posterior leaflet was in a direction opposite to that of the anterior leaflet. Because we were assessing the initial movement in this study, types 2 and 3 were grouped together as posterior movement of the posterior leaflet.

Analysis of these echocardiographic patterns was performed by an independent observer without knowledge of the surgical details of the mitral apparatus. There was no difference in the pattern of the leaflet movement when recorded by both Polaroid photography and on a strip chart.

Anterior movement of the posterior leaflet was observed in 25 patients and posterior movement in the remaining 7 patients (Table). These patterns were analysed according to the condition of the posterior leaflet and the dimensions of the mitral valve orifice obtained at surgery, and the EF slope and anterior leaflet amplitude. In 6 out of 7 patients in whom the posterior leaflet moved in a posterior direction (Fig. 2 and 3), the leaflet had minimal disease, in contrast to the 25 patients with an anterior movement (Fig. 4) of whom 20 had a posterior leaflet with extensive disease. This difference was significant $(P<0.01$ Fisher's exact test). These relations were still significant when the 4 patients with congenital or degenerative mitral valve disease were excluded from the analysis $(\mathbf{P}<0.05)$.

Table Surgical and echocardiographic data in 32 patients after mitral annuloplasty

\begin{tabular}{lllll}
\hline $\begin{array}{l}\text { Pattern of } \\
\text { leaflet } \\
\text { movement }\end{array}$ & $\begin{array}{l}\text { No. of } \\
\text { patients }\end{array}$ & $\begin{array}{l}\text { Valve orifice } \\
\text { at surgery } \\
\left(\mathrm{mm} / \mathrm{m}^{2}\right)\end{array}$ & $\begin{array}{l}\text { Valve } \\
\text { amplitude } \\
(\mathrm{mm})\end{array}$ & $\begin{array}{l}\text { EF slope } \\
(\mathrm{mm} / \mathrm{s})\end{array}$ \\
\hline $\begin{array}{l}\text { Anterior } \\
\text { Posterior }\end{array}$ & $25 \star$ & $21 \pm 0.6$ & $23 \pm 1.1$ & $46 \pm 3.5$ \\
$7 \dagger$ & $21 \pm 1.9$ & $24 \pm 1.8$ & $71 \pm 11.0$
\end{tabular}

Results expressed as mean \pm standard error of the mean.

*One with non-rheumatic disease.

†Three with non-rheumatic disease. 


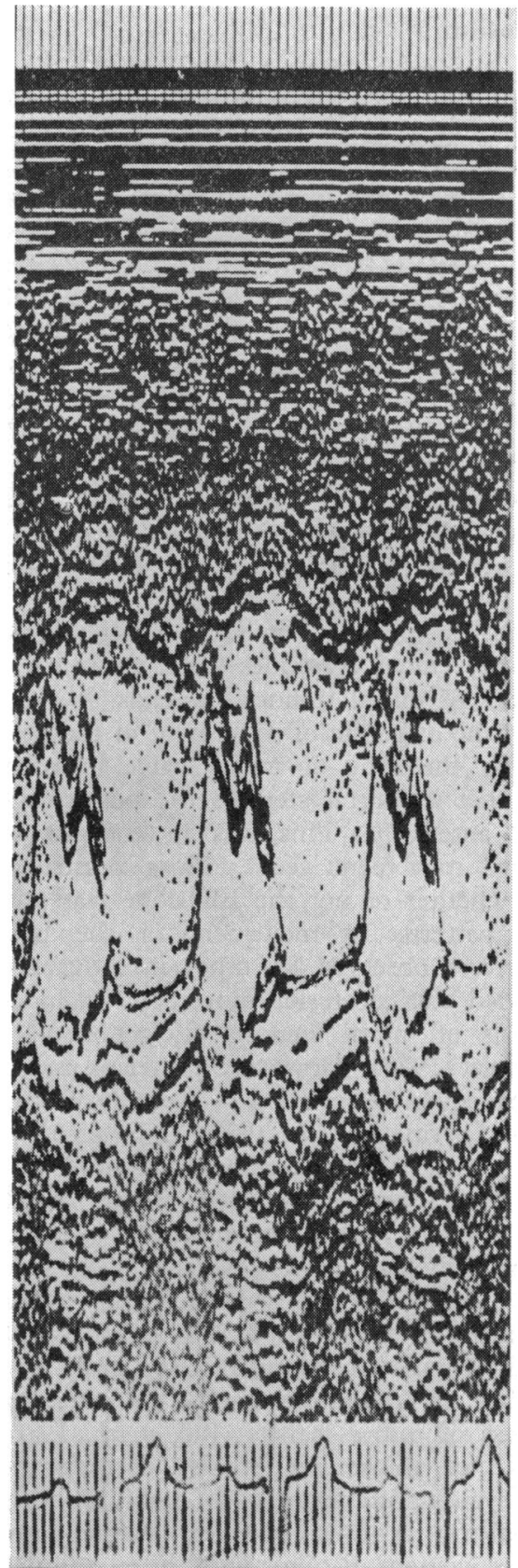

Fig. 2 Echocardiogram from a patient with posterior movement of the posterior leaflet (pattern 2).

The rheumatic and non-rheumatic patients have been grouped together in the analysis because the mean dimension of the mitral valve orifice, anterior leaflet amplitude, and EF slope were essentially the same. There was no significant

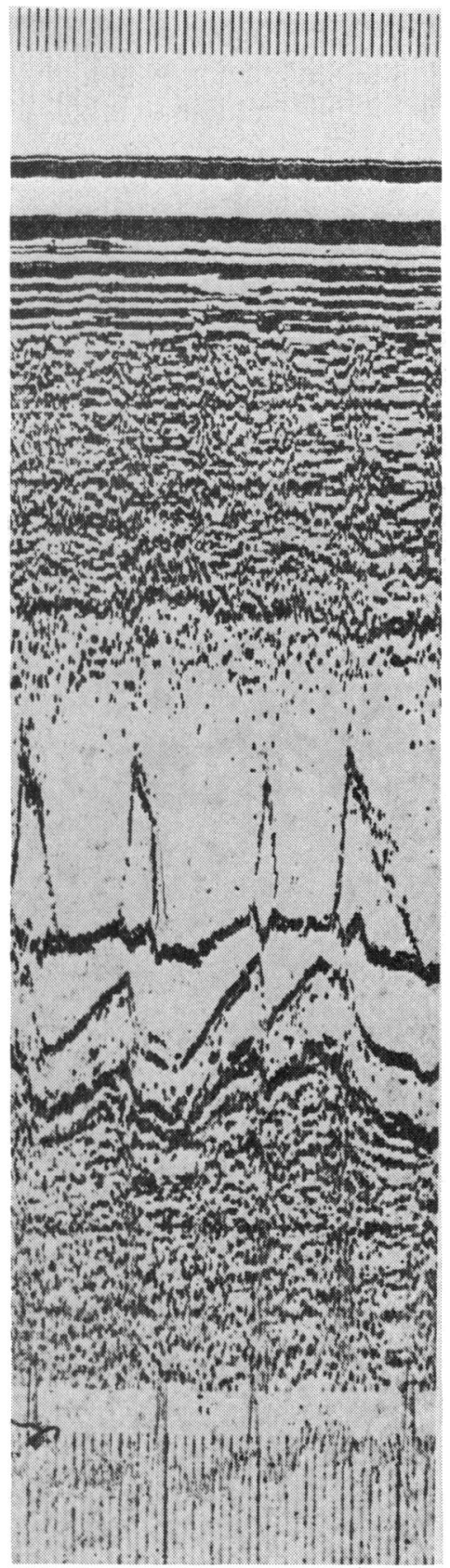

Fig. 3 Echocardiogram from a patient with posterior movement of the posterior leaflet (pattern 3).

difference in dimension of the mitral valve orifice or anterior leaflet amplitude between the 2 types of valve movement (Table). The mean ( \pm SEM) EF slope obtained from echocardiograms of patients with a posterior movement was signifi- 

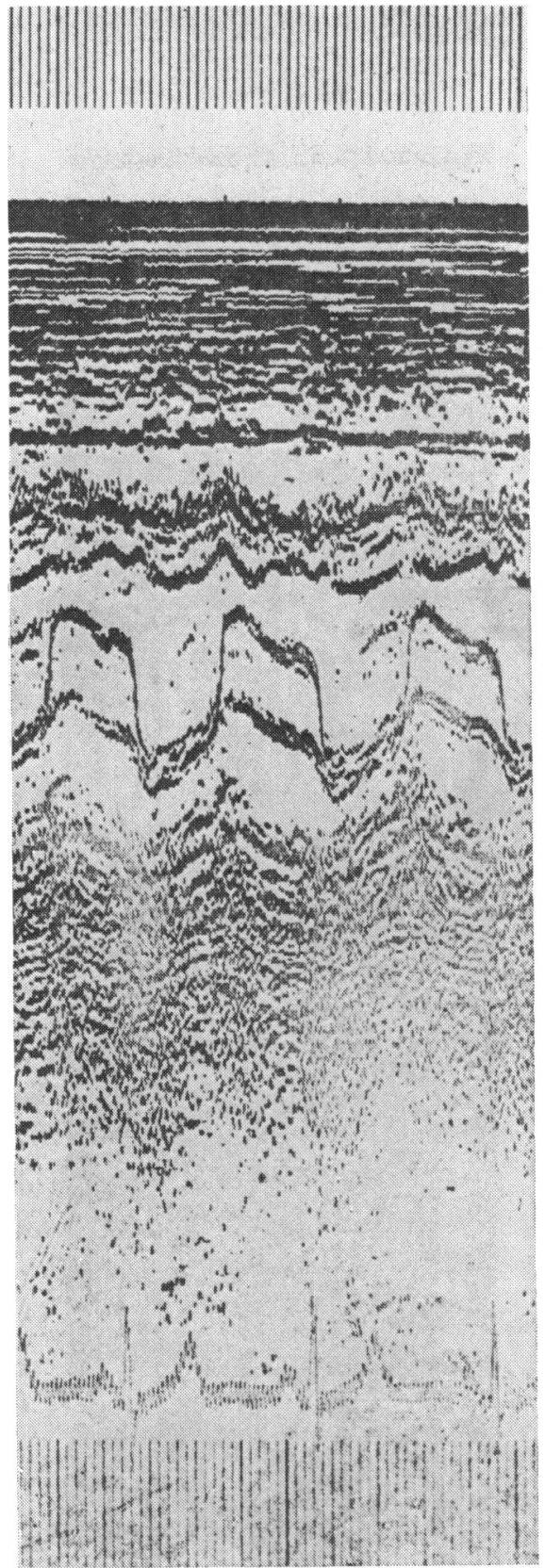

Fig. 4 Echocardiogram from a patient with anterior movement of the posterior leaflet (pattern 1).

cantly faster $(71 \pm 11.0 \mathrm{~mm} / \mathrm{s})$ than that seen in patients with anterior movement $(46 \pm 4.0 \mathrm{~mm} / \mathrm{s})$ $(P<0.05)$. Significance was assessed by Bailey's modification of Student's t test (Bailey, 1959).

\section{Discussion}

Analysis of the pattern of movement of the anterior mitral valve leaflets with echocardiography was introduced by Edler and Gustafson (1957). Reduction of the EF slope of the anterior leaflet remains an essential feature in the diagnosis of mitral stenosis (Edler, 1967). Investigation into the mechanism of movement of the anterior leaflet soon established that the EF slope was determined by the rate of left ventricular filling and movement of the mitral valve ring (Moreyra et al., 1969; Layton et al., 1973; Mary et al., 1973; Laniado et al., 1975). A reduction was therefore found to occur in conditions in which the cardiac output or the rate of ventricular filling was reduced, as well as in mitral stenosis (McLaurin et al., 1973; Quinones et al., 1974).

However, pattern analysis of the posterior leaflet movement continues to be of value in the diagnosis of mitral stenosis. Duchak et al. (1972) studied the direction of movement of the posterior leaflet at the time of mitral valve opening and found that in mitral stenosis the posterior leaflet moved anteriorly. This was in contrast to the posterior movement seen with a normal mitral valve, whether or not the EF slope was reduced. These patterns of movement of the posterior leaflet were observed by other investigators who concluded that posterior movement excluded the diagnosis of mitral stenosis (Feigenbaum, 1972; Teichholz, 1975). However, posterior movement was subsequently reported in patients with mitral stenosis (Berman et al., 1975; Cope et al., 1975; Flaherty et al., 1975; Levisman et al., 1975; Ticzon et al., 1975; Feigenbaum, 1976; Henry and Kastl, 1977). A controversy therefore exists in the use of analysis of the pattern of movement of the posterior leaflet, and this is partly because the underlying mechanism is unexplained. One of the problems in defining the mechanism stems from the unreliability of echocardiography in assessing the thickness of mitral leaflets (Raj et al., 1976). An estimate of thickening of the posterior leaflet, with resulting impairment of mobility, forms an essential part in any study to explain the pattern of leaflet movement. Patients with mitral annuloplasty were selected for study because the anatomy of the mitral valve can be directly examined during the operation. In addition, the surgical procedure, aimed at correcting the regurgitation, achieves this by producing commissural fusion, a feature common to all types of mitral stenosis. This operation was therefore used to investigate the relation of possible anatomical mechanisms to the echocardiographic pattern of movement. 
Several mechanisms have been suggested to explain the abnormal posterior leaflet movement. Duchak et cil. (1972) and Levisman et al. (1975) proposed that anterior movement of the posterior leaflet was dependent on the movement of the whole mitral apparatus, particularly the mitral ring. Feigenbaum (1976) and Henry and Kastl (1977) suggested that such movement was the result of commissural fusion which pulls the posterior leaflet in a direction similar to that of the anterior leaflet. These suggested mechanisms include the basic assumption that the mobility of the posterior leaflet is so impaired by thickening or fibrosis that movement of any of its parts follows the movement of the commissure or the annulus. The only hypothetical mechanism given to explain a posterior movement in mitral stenosis is that the posterior leaflet is still flexible and mobile (Berman et al., 1975; Levisman et al., 1975).

The present investigation has allowed a direct test of the hypothesis that movement of the posterior leaflet, shown by echocardiography, is basically determined by the pliability and mobility of the leaflet. The results have shown that a posterior movement was associated with a thin and mobile posterior leaflet and anterior movement was more frequently associated with extensive disease of the posterior leaflet. The absence of a significant difference in anterior leaflet amplitude between anterior and posterior movement was not unexpected, since a pliable anterior leaflet was a necessary prerequisite for annuloplasty (Wooler et al., 1962). This finding makes it unlikely that posterior movement is dependent on the presence of a reduced anterior leaflet movement as suggested by Henry and Kastl (1977). We found an increased EF slope in the group of patients with posterior movement, but Levisman et al. (1975) showed that 5 out of 54 patients with severe mitral stenosis had posterior movement. Though our patients are not strictly comparable with those of Levisman et al. (1975), it appears that a pliable posterior leaflet can exist in mitral stenosis regardless of the severity of the stenosis.

While anterior movement of the posterior leaflet excludes a normal mitral valve, the results in this study have shown that posterior movement cannot rule out the diagnosis of mitral stenosis. The findings in the study do not exclude a role for commissural fusion or valve ring mobility in anterior movement. However, the pattern of movement in the centre of the posterior leaflet, through which the ultrasound beam is directed, appears to be determined by the pliability of that leaflet.

\section{Addendum}

As this manuscript was being submitted we read the paper of Shiu et al. (1978). These authors have confirmed that posterior movement of the mitral leaflet occurs in mitral stenosis. In addition, they reported that this pattern of movement tended to occur in patients with less severe stenosis, though not exclusive of this, and that at operation greater mobility of both leaflets was found. It is not clear how the latter finding was assessed.

\section{References}

Bailey, N. T. J. (1959). Statistical Methods in Biology. English Universities Press, London.

Berman, N. D., Gilbert, B. W., McLaughlin, P. R., and Morch, J. E. (1975). Mitral stenosis with posterior diastolic movement of posterior leaflet. Canadian Medical Association fournal, 112, 976-979.

Cope, G. D., Kisslo, J. A., Johnson, M. L., and Behar, V. S. (1975). A reassessment of the echocardiogram in mitral stenosis. Circulation, 52, 664-670.

Duchak, J. M., Jr., Chang, S., and Feigenbaum, H. (1972). The posterior mitral valve echo and the echocardiographic diagnosis of mitral stenosis. American fournal of Cardiology, 29, 628-632.

Edler, I. (1967). Ultrasoundcardiography in mitral valve stenosis. American fournal of Cardiology, 19, 18-31.

Edler, I., and Gustafson, A. (1957). Ultrasonic cardiogram in mitral stenosis. Acta Medica Scandinavica, 159, 85-90.

Feigenbaum, H. (1972). Clinical application of echocardiography. Progress in Cardiovascular Diseases, 14, 531-558.

Feigenbaum, H. (1976). Echocardiography. Lea and Febiger, Philadelphia.

Flaherty, J. T., Livengood, S., and Fortuin, N. J. (1975). A typical posterior leaflet motion in echocardiogram in mitral stenosis. American fournal of Cardiology, 35, 675-678.

Henry, W. L., and Kastl, D. G. (1977). Echocardiographic evaluation of patients with mitral stenosis. American fournal of Medicine, 62, 813-818.

Laniado, S., Yellin, E., Kotler, M., Levy, L., Stadler, J., and Terdiman, R. (1975). A study of the dynamic relations between the mitral valve echogram and phasic mitral flow. Circulation, 51, 104-113.

Layton, C., Gent, G., Pridie, R., McDonald, A., and Brigden, W. (1973). Diastolic closure rate of normal mitral valve. British Heart Fournal, 35, 1066-1074.

Levisman, J. A., Abbasi, A. S., and Pearce, M. L. (1975). Posterior mitral leaflet motion in mitral stenosis. Circulation, 51, 511-514.

McLaurin, L. P., Gibson, T. C., Waider, W., Grossman, W., and Craig, E. (1973). An appraisal of mitral valve echocardiogram mimicking mitral stenosis in conditions with right ventricular pressure overload. Circulation, 48, 801-809.

Mary, D. A. S., Pakrashi, B. C., Wooler, G. H., and Ionescu, M. I. (1973). Study with reflected ultrasound of patients with mitral valve repair. British Heart fournal, 35, 480-487.

Moreyra, E., Klein, J. T., Shimada, H., and Segal, B. L. (1969). Idiopathic hypertrophic subaortic stenosis diagnosed by reflected ultrasound. American fournal of Cardiology, 23, 32-37.

Quinones, M. H., Gaasch, W. H., Waisser, E., and Alexander, J. K. (1974). Reduction in the rate of diastolic descent of the mitral valve echogram in patients with altered left 
ventricular diastolic pressure-volume relations. Circulation, 49, 246-254.

Raj, M. V. J., Bennett, D. H., Stovin, P. G. I., and Evans, D. W. (1976). Echocardiographic assessment of mitral valve calcification. British Heart fournal, 38, 81-84.

Shiu, M. F., Jenkins, B. S., and Webb-Peploe, M. M. (1978). Echocardiographic analysis of posterior mitral leaflet movement in mitral stenosis. British Heart fournal, 40, 372-376.

Teichholz, L. E. (1975). Echocardiography in valvular heart disease. Progress in Cardiovascular Diseases, 17, 283-302.

Ticzon, A. R., Damato, A. N., Caracta, A. R., Lau, S. H., and Gross, L. (1975). Echocardiographic manifestation of "false" mitral stenosis that was. Annals of Internal Medicine, 83, 503-505.

Wooler, G. H., Nixon, P. G. F., Grimshaw, V. A., and Watson, D. A. (1962). Experience with the repair of the mitral valve in mitral incompetence. Thorax, 17, 49-57.

Requests for reprints to M. I. Ionescu, Esq., F.A.C.S., Department of Cardiothoracic Surgery, The General Infirmary, Leeds LS1 3EX. 